\title{
APPENDICEAL KNOTTING CAUSING SMALL BOWEL OBSTRUCTION: A CASE REPORT
}

Sachin Kadlewad ${ }^{1}$, Shailesh Kannur², Girish Kullolli ${ }^{3}$, Deepak Chavan ${ }^{4}$

\section{HOW TO CITE THIS ARTICLE:}

Sachin Kadlewad, Shailesh Kannur, Girish Kullolli, Deepak Chavan. "Appendiceal Knotting Causing Small Bowel Obstruction: A Case Report". Journal of Evolution of Medical and Dental Sciences 2015; Vol. 4, Issue 73,

September 10; Page: 12787-12789, DOI: 10.14260/jemds/2015/1840

ABSTRACT: Acute appendicitis is a clinical entity that presents with typical characteristics in young patients. Appendix as a cause of intestinal obstruction is uncommon and not always suspected. The gut entrapped by the appendix, acting as constricting band causes intestinal obstruction and can cause gangrene of bowel if not intervene early. Only 11 cases are reported till date. We present a case of appendicular knot in a young male patient.

KEYWORDS: Appendix, Knotting, Small bowel obstruction.

INTRODUCTION: The first description of appendix was described in $16^{\text {th }}$ century. ${ }^{1}$ Amyand is credited with the first appendicectomy in 1736 on exploration of hernia he discovered appendix. ${ }^{2}$ acute appendicitis is a clinical entity that presents with typical characteristics in young patients. However, in older patients the symptoms and laboratory tests can be non-specific. ${ }^{3}$ Appendix as a cause of intestinal obstruction is uncommon and not always suspected. Although it was described as early as 1901, very few reports are available which do a comprehensive review.

Appendicular band syndrome also called as appendicular knot or appendicular tie syndrome is an extremely rare surgical entity. About 11 cases are reported so far. ${ }^{4}$ it usually presents with intestinal obstruction. The gut entrapped by the appendix, acting as constricting band, may strangulate leading to gangrene, if not intervened early. Preoperatively it is very difficult to diagnose the appendiceal knotting. The diagnosis is always made at the time of appendicectomy or laparotomy.

CASE REPORT: A 28-years-old male patient presented to casualty with complaints of acute onset lower abdominal pain, fever and vomiting for 3 days. There was no past history of abdominal surgeries. On physical examination, patient's vitals were stable. Abdominal examination revealed features of acute appendicitis. Blood investigations were normal except the presence of leukocytosis. On ultrasound of abdomen shows probe tenderness at the right iliac fossa and appendix was not visualized.

A decision was taken to go ahead with appendicectomy under spinal anesthesia on emergency basis. Grid iron incision was taken to open the abdomen in layers. Appendix could not be visualized initially and distended small bowel was noted. The incision was extended and appendix was visualized. Appendix was inflamed and measured about $14 \mathrm{~cm}$ in length. A constriction ring was formed by the appendix at the terminal ileum causing small bowel obstruction.

The tip of the appendix was inflamed and adherent to the ileum forming a knot constricting the distal ileum. The small bowel proximal to the knotting was distended and the base of the appendix was located and retrograde appendicectomy was done and sent for histopathology. The patient had an uneventful recovery. Histopathology reveals acute appendicitis. 


\section{CASE REPORT}

Figure No. 1: Shows the Appendicular Knot causing Obstruction of the Small Intestine.

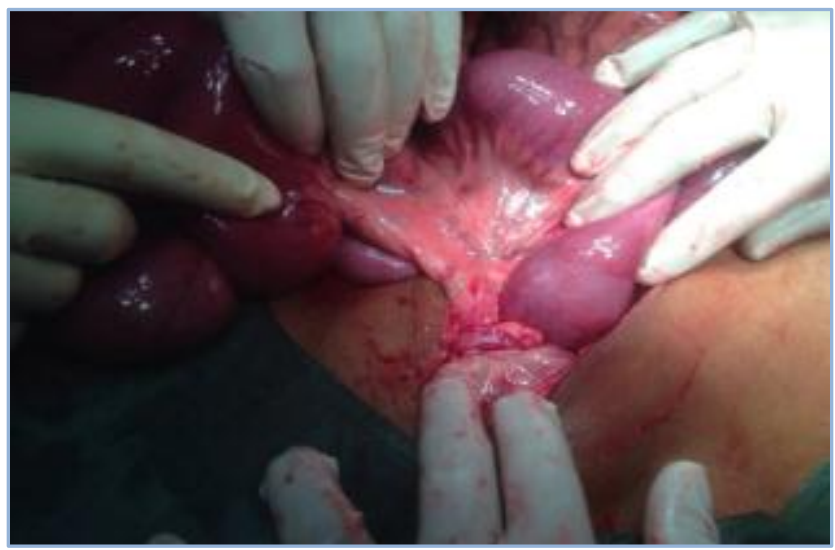

Figure 1

Figure No. 2: Shows distention of proximal bowel due to obstruction by appendix

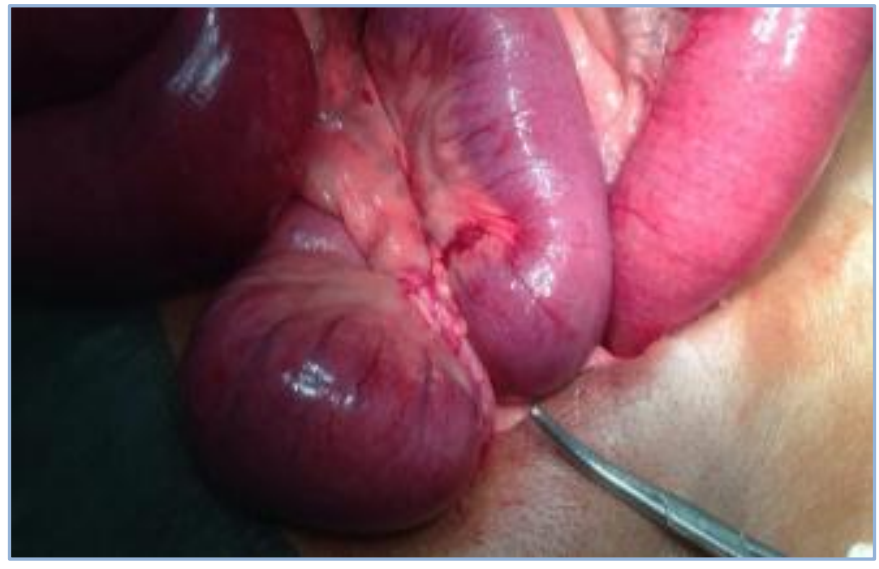

Figure 2

DISCUSSION: Small bowel obstruction as a complication of acute appendicitis may be a dynamic or mechanical. Paralytic ileus caused by appendicular inflammation is the most common cause of intestinal obstruction in acute appendicitis occurring in 1-5\% cases of appendicitis. ${ }^{5}$ Mechanical obstruction due to an inflamed appendix is a very rare entity. It can be associated with or without strangulation may result from wrapping of appendix around a bowel loop or adhesion of the appendicular tip with small bowel, cecum or posterior peritoneum forming a ring like structure known as an appendicular knot.

A portion of small bowel usually herniates through that ring or knot forming a closed loop obstruction with or without strangulation. In the view of mobility and variable position of the tip of appendix, it is possible that the appendix may get adhered to adjacent structures during the phase of inflammation giving rise to pathology Appendix adhere to the adjacent structures, as appendix is a mobile organ with many variations in its normal position. During the initial event of appendicular inflammation, it would get adhered to surrounding structures producing various pathologies mentioned above. Increased length of appendix logically seems to predispose to such an event. ${ }^{6}$ 
In our case the tip of inflamed appendix was adherent to the wall of distal ileum, with the body of appendix wrapped around ileum leading to formation of a constricting ring, thus leading to mechanical small bowel obstruction.

\section{BIBLIOGRAPHY:}

1. Meade RH, An introduction to the history of general surgery, Philadelphia, PA: Saunders; 1968.

2. William H, Douglas S. Appendix, Meckel's and other small bowel diverticula; Maingoat's Abdominal operation; 12 ed: 2013; 623-24.

3. Kraemer M, Franke C, Ohmann C, Yang Q. Acute appendicitis in late adulthood: incidence, presentation, and outcome. Results of a prospective multicentre acute abdominal pain study and a review of the literature. Langenbecks Arch Surg. 2000; 385:470-81.

4. Assenza M, Ricci G, Bartolucci P, Modini C. Mechanical small bowel obstruction due to an inflamed appendix wrapping around the last loop of ileum. G Chir. 2005; 26:261-6.

5. Bhandari L, Mohandas P. Appendicitis as a cause of intestinal strangulation: A case report and review. World J Emerg Surg. 2009; 4:34.

6. Assenza M, Ricci G, Bartolucci P, Modini C. Mechanical small bowel obstruction due to an inflamed appendix wrapping around the last loop of ileum. G Chir. 2005; 26:261-6.

\section{AUTHORS:}

1. Sachin Kadlewad

2. Shailesh Kannur

3. Girish Kullolli

4. Deepak Chavan

\section{PARTICULARS OF CONTRIBUTORS:}

1. Post Graduate, Department of General Surgery, Shri B. M. Patil Medical College and Hospital, Bijapur.

2. Senior Resident, Department of General Surgery, Shri B. M. Patil Medical College and Hospital, Bijapur.

3. Associate Professor, Department of General Surgery, Shri B. M. Patil Medical College and Hospital, Bijapur.

FINANCIAL OR OTHER COMPETING INTERESTS: None
4. Assistant Professor, Department of General Surgery, Shri B. M. Patil Medical College and Hospital, Bijapur.

\section{NAME ADDRESS EMAIL ID OF THE CORRESPONDING AUTHOR:}

Dr. Sachin Kadlewad,

S/o. Dr. Shivasharan Kadlewad,

Kadlewad Hospital,

Near Desai Circle,

Jamakhandi-587301,

District: Bagalkot,

E-mail: drsachin5885@rediffmail.com

Date of Submission: 21/08/2015.

Date of Peer Review: 22/08/2015.

Date of Acceptance: 04/09/2015.

Date of Publishing: 10/09/2015. 